\title{
Nature Restoration Technologies as a Tool for Urbanisation Management
}

\author{
Elena Zaykova*
}

Moscow State University of Civil Engineering, Yaroslavskoe shosse, 26, Moscow, 129337, Russia

\begin{abstract}
Urban management is a new terminology in global urban planning, actively influencing the indicators of environmental sustainability and actions in relation to various climate risks on the planet. Experts consider different types of technologies as an opportunity to manage urbanization at the global level and predict the situation in the socioeconomic and environmental spheres of life. On the other hand, the increasing risks on the planet from floods, hurricanes, fires and droughts force specialists to adapt to these changes, learn how to control them through new design technologies. Therefore, the emergence of the term "urban management" is not accidental and is associated with a change in the perception of the level of sustainability of the environment, the comfort of living for people of different ages and social status in large cities. In this regard, the assessment and meaning of such well-known concepts as "Sustainable City", "Green City", "Smart City" changes somewhat. Their content is filled with a new meaning if the technological aspect is added to the socio-economic and environmental aspects of sustainable development, as an independent concept associated with the restoration of the natural potential of cities by technological means. Therefore, the article will consider the problems of restoring nature and urbanized territories through the use of ecological technologies that simulate natural processes with different typological content: from the restoration of biotopes to the accumulation of rainwater in the body of the natural landscape.
\end{abstract}

\section{Global trends}

Analyzing publications on world architectural and urban planning projects, we can confidently state the processes of stable integration of environmental technologies into the facade space of buildings and the urban landscape [1, 2, 3]. At the same time, the sociocultural scenario in such objects involves the use of blue-green technologies to create a new socio-cultural scenario for users of different ages and social status, as well as the creation of comfortable recreation areas in a natural and sustainable, from the point of view of time, environment. These natural components create scenarios of population activity and give the object signs of identity, although they are initiated by technological means. Green roofs, vertical landscaping, building-forest, forms of artificial terrain as protection from noise and

* Corresponding author: lena_landscape21@mail.ru 
wind, collection and redistribution of rainwater at different urban levels and surfaces - all these technologies over the past 20 years are not considered in isolation from each other-only in the building or in the landscape. They are presented interest to specialists on the field of urban planning forecasting and design as new opportunities in the implementation of projects of different typological structures and in different parts of the city where there is or is not a shortage of territories. Just the latter option provides ample opportunities for testing and implementing technological innovations in order to renovate urbanized areas or restore natural areas in the structure of the urban fabric, but with new means. Disclosure of potential land development and restoration of the natural frame of cities by means of technology determines the future development of urban planning theory and practice in the XXI century [4].

Projects such as, for example, the concept of the architectural firm OMA to adapt the master plan of two abandoned railway stations to the north and south of the periphery of Milan (Masterplan of Milan's Disused Railway Sites) with the creation of a park space accumulating volumes of rain surface water, revolving around the concepts of environmental filters and adaptive development, the project of the Copenhagen architectural firm SLA, which won the prestigious Nordic Built Cities Challenge Award, which presents " ... the natural climate adaptation of Copenhagen - ...a way to use nature, create better and more livable cities" [2,4], the project of the MTDA bureau - "Linear Forest" in the district of Amiens-Paris, where the linear object works as an ecological corridor in the contour of the ring road with recreational, transit and environmental functions, as well as many others, with the realized idea of using technology as a criterion for the restoration of the urban area. "Green " technologies stimulate the development of a socio-cultural scenario for all age groups, a new economic model of the object itself and its environment, as well as a space with a natural infrastructure that is stable over time (Fig. 1) [5]. The analysis of projects reveals the potential and prospects for the restoration of urban areas based on different types of technologies, which contributes to improving the aesthetic and environmental qualities of the new environment.

Exactly in technological solutions, especially the integration of different types of technologies in one design solution, in their competent use by specialists, that the opportunities for managing urbanization appear, for example, reducing the risks of noise and pollution, as well as wind and water loads on the projected site. The main direction in the popularization of such projects is the study of climatic features in the integration region. The issues of survival in the conditions of global urbanization are becoming more and more urgent, so humanity needs a perspective on not only the economic and social scenario of development, but also guarantees of environmental stability, which is primarily due to the increasing risks on the planet from floods, hurricanes and droughts. 


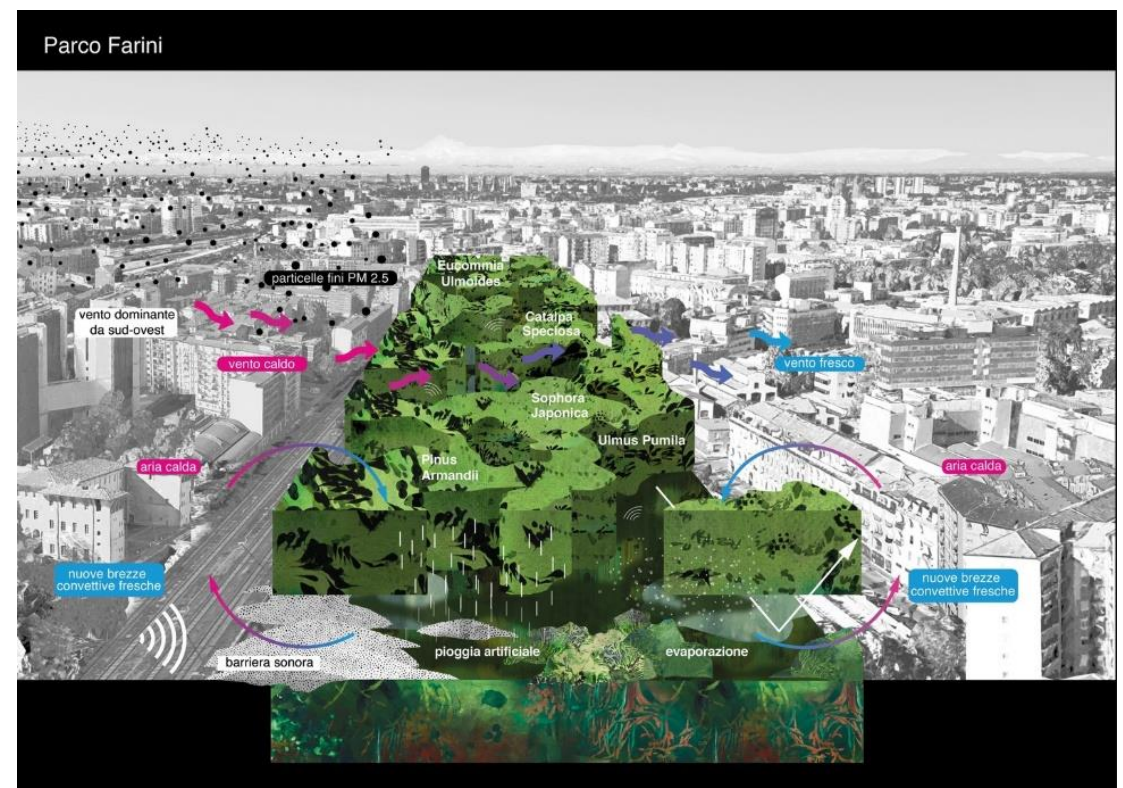

Fig. 1. Master plan of the OMA architectural bureau for the reconstruction of Scalo Farini and San Cristoforo - Milan [2]

In the trends of modern urban planning - a change in approaches towards long-term environmental and economic programs, in which the leading role is played by sustainable nature. It holds back and accumulates climate risks on the planet in terms of rainwater, is capable of development without the traditional expensive maintenance, and makes it possible even to engage in gardening and agro-landscapes, as it is supported by urban-planning "nanotechnologies". They, in turn, provide both stability and stability over time, since on their basis, experts predict the development of urban areas both dispersed and compact for many decades to come [3]. Therefore, it is no coincidence that the world urban planning community has been systematically introducing technological innovations in different countries over the past decades, especially with long winters. For a deeper understanding of the stages of development of different types of technologies that mimic natural processes, it is necessary to turn to the history of the issue, analyze the landmark projects of the direction and assess the possible risks in choosing solutions to the path of megacities to sustainable development due to technological progress in the XXI-st century.

\section{Methods}

\section{Imitation of the natural framework}

The ideas of the development of park and urban spaces according to the version of natural urbanism due to the" imitation " of natural ecosystems can be observed throughout the XX century in the works of famous architects, urbanists, landscape architects and designers of the urban environment. These searches are not accidental and originate from small private land and gardens, where for the first time an attempt is made to gently integrate the urban needs of a private customer into the natural environment and offer this transition by some new means. The absence of visible borders between the natural and man-made landscape is 
probably the main idea of the projects of the last century. Such masters as Frederick Gibberd, Pamela Copeland, A E Bye, Piet Oudolf and Gilles Clement in their works were able to repeatedly emphasize the beauty of the natural landscape, but at the expense of the dynamics and plastic forms of artificial second nature. These were the first projects in which an attempt was made to "observe" the nature and structure of the natural biotope to create undergrowth and edges by analogy with natural woodlands $[6,7,8]$. And the first works that study technologies for integrating "artificial" garden forms into the natural landscape of a place based on the principles of ecological design. This technique implies the creation of a new plant community based on the natural biotope and plants of this climatic zone, which requires minimal costs for subsequent maintenance and development in an urbanized environment.

Private estates with forest plots in the structure of the territory represent a great potential for the plastic integration of architectural objects into the surrounding natural landscape. Working on the contrast of natural and artificial materials with the silhouette dominance of one of them, the author of the project, as a rule, creates an identical image of the place in which the nuanced changes in the composition are remembered [8]. The use of natural nature as the background of a landscape composition allows us to reveal the plastic techniques of clashing styles or textures of materials both in the twentieth and in the twenty-first centuries, revealing new possibilities for imaginative interpretation of the natural territory with the help of landscape tools. The relationship between the preservation of the natural potential of the site and additional landscaping is still the main issue of modern green technologies and affects the ecological directions of the restoration of territories. The beginning of such research was laid by projects in which the main idea was to preserve the nature of the place and its soft addition with landscape means for a more natural composition as a whole.

In this approach, there is a competent shift of emphasis on working with the natural biotope of a particular area of urban or suburban territory and involves deep knowledge of the dynamics of the development of tree and shrub species, perennial cereals and meadow crops. A detailed study of the biotope allowed specialists to supplement it with garden plants of the local flora and to obtain a variant of soft integration of "artificial forms" as an easy complement to the natural situation [8]. Smart integration of a range of ornamental trees and perennial flower crops on the principle of forest edges and clumps became one of the areas of eco-technologies for the transmission of figurative language natural biotope using plastic endemic plants [8]. The projects of Sir Frederick Gibberd - "The Gibberd Garden" (1956), Pamela Copeland - "Mount Cuba Residence" (1960), "Leitzsch Residence", author of A E Bye (1970) and the garden "Hummelo" - the famous Piet Oudolf, 1982 supported the interest in working with natural sites and gave direction to the development of technologies for the restoration of natural and urbanized sites in the XXI-st century.

\section{"Artificial" water in the natural environment}

At the same time, there are projects dealing with water in which an attempt is made to move away from traditional ideas of water in the landscape composition of the land to its natural collection and processing of endemic plant communities are Grouped on the principles of caveat community of plants on the water and in the water, being the imitation of a natural oasis, can complement the picture of the natural landscape in the form of wetland area or even a private swamp. So in the Villa Mairea in the project of 1939 (architect Alvar Aalto) in a simple forest clearing, surrounded by a pine forest, an asymmetrical pool is included, resembling a natural lake [8]. The author of the project can rightly be considered the founder of the humanistic approach in architecture, when the harmony of the composition is achieved through the soft integration of architectural objects into the landscape of the place. And following the traditions is actively supported by competent work in harsh climatic conditions 
with endemic plants, observing nature and creating water bodies in open forest areas and moistened edges by analogy with natural woodlands.

The area of interest of the architect Ron Lutsko Jr in the garden "Sustainability Gardens at Turtle Bay" is based on the search for a landscape model in which development takes place based on the needs of both real users of this landscape, and the plant community and the ecological context of the composition scheme itself. In a 2003 project, he calls such an idea "long-term design" in combination with the Modernist approach of using appropriate materials at the design site. However, in the plan, we observe the smooth lines of a winding stream surrounded by stone paving, and the design pays attention to the climatic conditions of the area and uses local plants and materials. Rhone's "Sustainability Gardens" are a place of recreation in a natural setting and are used as an interactive landscape. Their goal is to introduce visitors to local ecological systems and to reveal the role of humans in their preservation over time [8]. In the presented project, the semantic image of the natural stream line is transformed into lines and forms of an eco-landscape with rainwater harvesting and planting of cereals, and meets the modern principles of sustainable conservation and development of territories using local flora.

The conservation and addition of the natural biotope by the plant community on the principles of contrast and nuance is of interest to specialists at the present stage as new principles for the conservation and maintenance of natural and specially protected areas, as well as the restoration of peripheral areas in their contour. The direction serves the goals of sustainable development of urban areas and has given rise to projects with a technological basis, in which the collection, movement and redistribution of rainwater is given increased attention as a means of changing the microclimatic parameters of the environment and identifying a place in the urban fabric.

\section{Results}

\section{Building nano-technologies in the structure of the urban fabric}

In general, the presented sample is a clear guide for a comprehensive study when you are working with the habitat of different typological structure, but also moisture that reveals new opportunities for the use of green technologies for the management of urbanization and in different parts of the urban area - in the middle, and a peripheral area where there is a reserve areas and can be adapted to the nature of the wastelands to a new socio-cultural scenario. In the presence of terrain, it is possible to naturally collect surface rainwater and, with the help of the plant community, filter it. This shows the regularity of the development of biotope technologies in the XXI century, but the urban planning emphasis on the use of technologies in creating ecosystems in urban space has changed, aimed at maximizing the possibilities of nature for self-support.

\section{Technologies of imitation of a natural biotope}

Further improvement of technologies for the stabilization, addition and adaptation of the natural biotope to the new socio-cultural and recreational needs of megacities is being developed in landmark projects for specialists where it is possible to simulate meadow spaces, woodlands or to purify rain and surface water through filtration. The creation of meadows of different types is one of the modern and popular areas in which the landscape theme of "new wave flower beds" or modular planting of cereals develops. Or to supplement 
the structure of the wasteland biotope with cultivated plant species in areas where there has been no exploitation for a long time, for example, on former railway lines. A striking example of such projects are the parks of Germany - der Park am Nordbahnhof and der Park am Gleisdreieck in Berlin [9], where the public park space is formed on the basis of the structure of vacant lots and supplemented with decorative plantings that can enliven the natural landscape (Fig. 2).

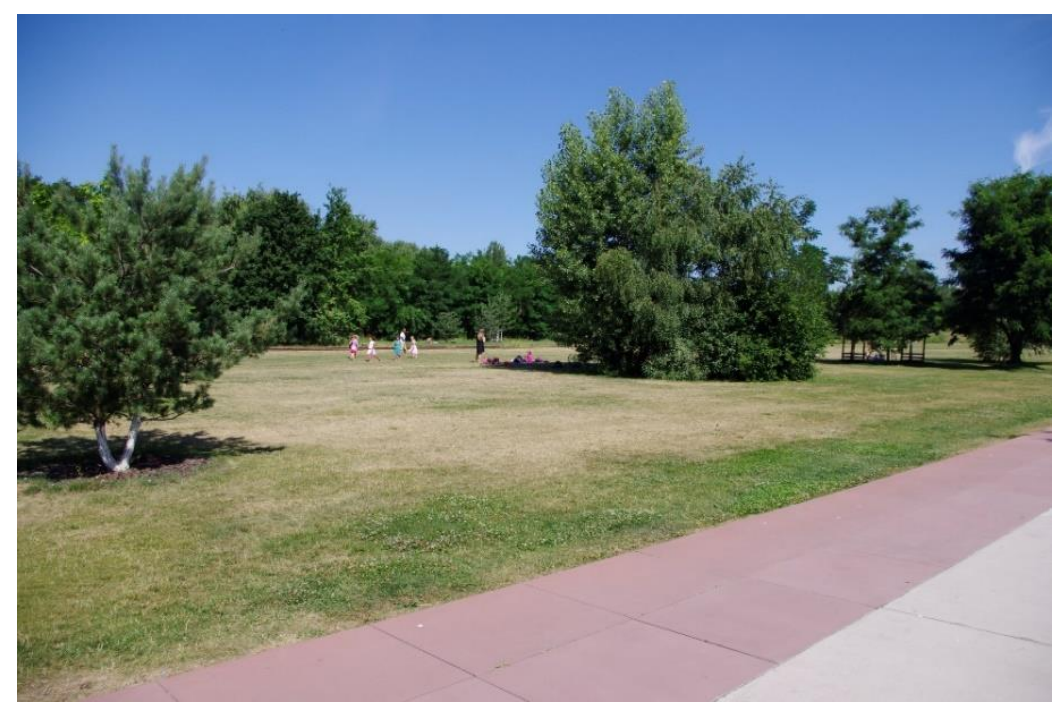

Fig. 2. Der Park am Gleisdreieck-the urban planning concept is based on the preservation of natural biotope on the site of the former and in the contour of the current railway communication - Berlin, Germany (photo by author)

So the park der Park am Gleisdreieck in Berlin, Germany is a vivid example of using the potential of "spontaneous" nature, when a park space is organized on the basis of a natural oasis formed over decades, which allows you to get the maximum effect with minimal investment. All projects preserve the continuity in the development and present the principles and methods of "green" technologies for the restoration of park spaces, the maintenance of natural biotope by means of "second" man-made nature on the periphery of such objects and in different parts of the urban space.

More than half a century of improving technologies in the world of urban planning illustrates the professional approach and wide opportunities for the renovation of sites and the restoration of the natural framework of cities, as well as new opportunities in the engineering preparation of territories. A continuation of the theme of natural biotopes on an artificial basis is the American project of the Bjarke Ingels Group (BIG). The company has released details of its project "Covers Brooklyn Highway in Landscape Waterfront Park" - a landscape urbanism in Brooklyn, New York, turning the roof of a six-lane highway into a connected park space between the city and the waterfront. At the center of the scheme is the Robert Moses-designed Brooklyn Queens Expressway, built in the 1960s (Fig. 3) [10]. 


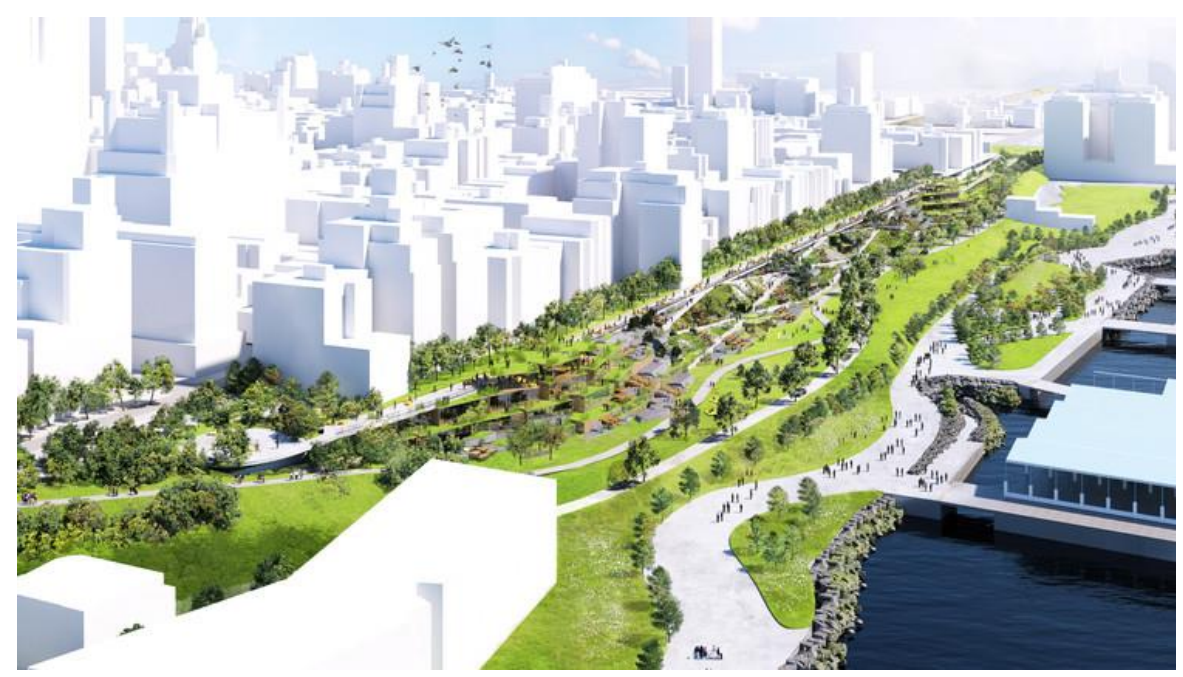

Fig. 3. BIG published the project "Covers Brooklyn Highway in Landscape Waterfront Park" of landscape urbanism in Brooklyn - USA [10]

The first step in the BIG scheme is the construction of a full-fledged roadway along Furman Street and Brooklyn Bridge Park, which is essentially the integration of technology between the exploited tunnel roof with forms of geoplastics and artificial landscape along the shoreline. This design provides for the addition of a significant number of new park areas along the little-used waterfront corridor, connecting Brooklyn Heights and Brooklyn Bridge Park with a series of intersecting areas with artificial hills as places of protected recreation and isolation from urban noise. [10] Here, greenery and park spaces in the form of open areas can accumulate significant amounts of water in natural disasters and floods, demonstrating new opportunities in the management of urbanization through environmental technologies.

\section{Urban forest restoration technologies}

In the examples listed above, implemented in different years and in different cities, we can note the active use of technologies in changing the environmental characteristics of the environment and creating ecosystems for different functional purposes and sections of urban territory. The issues of decompression of buildings and rethinking the reserve of urban territory while reducing the huge areas of sealed surfaces, restoring nature and preserving natural territories by various means remain the main ones in the concept of sustainable development at the present stage. Restoration of sustainable areas in the contour of natural territories, former industrial zones and sections of railway and transport communications should be carried out on the basis of new technological solutions that can return natural biotopes to a state of stability, a stable ecological model. One of the projects implemented over the years is the Linear Park-an ecological corridor-along the motorway and office buildings in Paris-arrondissement of Amiens, providing alternative rainwater management, where simulated forest landings can collect rainwater and use it at the forest scale (Fig. 4) $[5]$. 


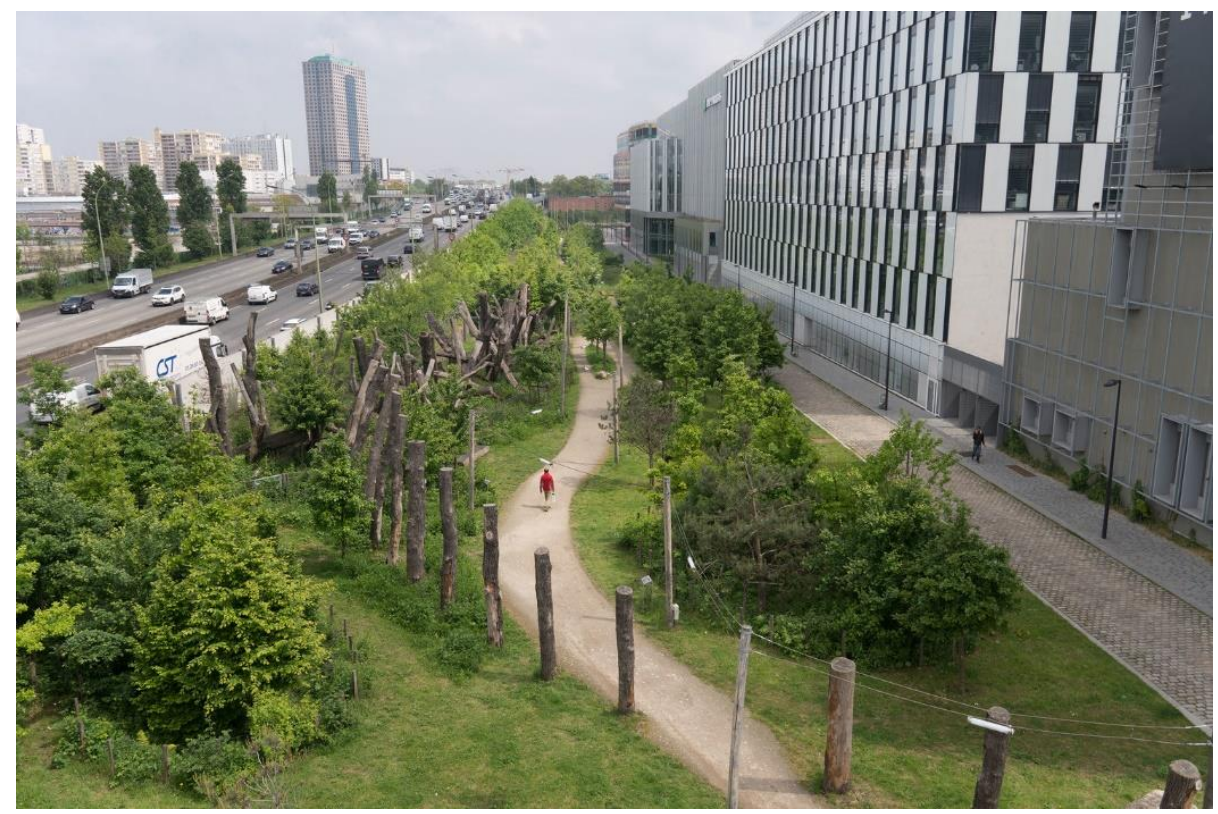

Fig. 4. Linear Park as an ecological corridor restored with modern technologies - Amiens, France [5]

The project invests in a derelict urban area, transforms it into quality public spaces, and eventually provides the site with a forest area of about 24 hectares in the range of 100 to 150 $\mathrm{m}$ in the contour of the ring road. The project is the first section of forest in a problematic place for the city - in the contour of transport communication.

The project solves several socio-economic, environmental and technological problems: - creates an ecological corridor in which the forest is a noise-proof wall and creates a buffer zone for office buildings, fights pollution and temperature fluctuations in different seasons due to the presence of trees in the array.

- organizes the natural area, restoring ecological functioning: the forest will eventually become a stable public space, where due to the decomposition of leaves, humus is formed, which forms a nutritious litter for trees and various types of undergrowth, maintaining the structure of the formed natural biotope in balance.

- the structure of public spaces in the ring road contour: the forest confirms the possibility of developing and maintaining ecosystems in urban environments created by new technologies; - creates a new socio-cultural scenario for residents and employees, offering new spaces for recreation: Jogging, cycling, and linear forest connect the Canal Saint-Denis with the La Chapelle quarter, creating a green oasis [5].

The forest area is a unique space for residents of the nearest areas, offers a positive alternative to the neighborhood of the ring road and is designed with new technologies. The forest available in these areas for recreation offers walks, connects different areas, and its maintenance technologies allow collecting and redistributing rainwater for the entire oasis.

\section{Technologies of filtering biotopes for rain and surface water with the system of agricultural landscapes}

When the landscape acts as the main typological unit of the urban fabric, which can, with the support of the latest green design technologies, return the urban environment to a state of ecological balance, it can also support the sustainable urban development of territories for 
many decades to come. When working with water, more stable objects are characterized by solutions depending on the typology of the landscape and the selected environmental technologies $[11,12]$. These can be urban trees in the rainwater filtration system and open channels for the movement of rainwater to the collection point, urban biological reservoirs, urban gardens, rainwater collection and storage of water volume with subsequent use in the structure of the park space. Abandoned or degraded areas of urban fabric with a dominant landscape feature have a high potential to improve the ecological qualities of the environment where there is a reserve of territories. These include areas with "spontaneous" nature, vacant lots, the near contour of natural territories and railway communications, as well as areas of industrial zones that can be renovated with new technologies, especially for rainwater filtration, to set a new social scenario for development in the city $[3,11]$.

Such well-known projects of the architectural bureau Turenscape, China as: Suzhou Zhenshan Park, Yongning River Park (floating gardens), Puyangjiang River Corridor (Greenway), Mei Flower Garden, Liupanshui Minghu Wetland Park or Qian'an Sanlihe Greenway for the development of a master plan of former industrial and polluted areas with the creation of a park space with the history of the place, agro-landscapes and accumulating volumes of rain surface water and their filtration in the aquatic biotope are a bright guide for adaptation of new methods and tools for countries with different climatic zones [13,14]. One of the profile projects on the theme of "new water" is, without a doubt, the implemented project of the Thomas Balsley Associates team, which in 2014 won the prestigious international competition of the American Society of Landscape Architects (ASLA) with the project "Hunter's Point South Waterfront Park" (Fig. 5) [15].

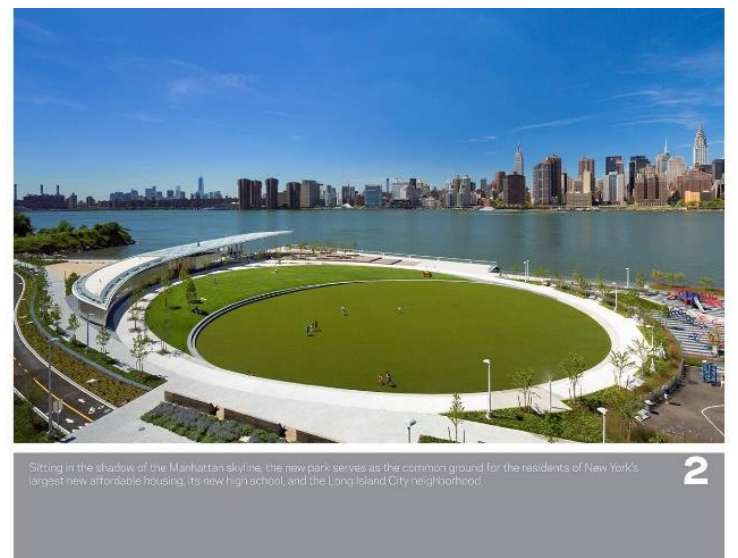

Fig. 5. Thomas Balsley Associates - project «Hunter's Point South Waterfront Park», USA [15]

The combination of technological innovations and the renovation of the wetland industrial area along the water area has contributed to the creation of an open park space with sustainable components of nature in the urban environment. The green corridor forms functional transit and recreation zones that can accumulate surface water and its volumes in the natural biotope structure of the park due to the lowering of relief markers. It was in this project that the professional team of the bureau applied and once again worked out bluegreen technologies for collecting, redistributing and diverting rainwater, preserving the stability of the plant community selected by specialists in the field of dendrology, biology and soil science, once again demonstrating the prospects for technological progress at the present stage. 


\section{Conclusion}

In conclusion, it is necessary to note the leading role of environmental technologies in maintaining the concept of sustainable development of the territory, the formation of a city model with natural components and a new socio-cultural scenario of the urban environment. As noted above, in the world practice, we observe continuity in the choice of principles and methods for the reconstruction of urban areas in the new century, and they are primarily related to the issues of improving the technologies of blue-green infrastructure. The criteria for walking distance to nature and green areas are laid down in the master plans for the development of many cities in the coming years, as a response to the challenges of global urbanization.

To this can be added the processes of climate change, the problems of flooding and the provision of food to the population. In the fight against the negative effects of globalization, eco-technologies have a huge resource in changing the quality of the urban environment and predicting climate risks, opening up opportunities for the first steps in the management of urbanization. And this is a completely different perspective of urban planning forecasting and design, as well as the science and methodology of urban planning at the present stage.

\section{References}

1. Dr. Tan Puay Yok. 2013, Vertical Garden City: Singapore / Tan Puay Yok; with contributions by Manfred Koehler, Steven Peck, Linda Velazquez. - Singapore: Straits Times Press, ISBN: 978-981-4342-59-9, pp.191

2. https://www.archdaily.com/915510/how-three-major-us-cities-are-preparing-forclimate-hange?utm_medium=email\&utm_source=ArchDaily\%20List\&kth=1,846,414 (12.04.2019)

3. Making Cities Liveable. Blue-Green Infrastructure and Its Impact on Society. www.ramboll.com/ planning-and-urban-design, pp. 18

4. Losantos, Agata. Urban Landscape. FKG. ISBN 978-84-96936-81-2, 2008, p.255

5. https://arpente.re/work/eco-quartier_(14.06.2020)

6. Zaykova, E. Yu. Ecological design in the urban environment: the semantic language of modern landscape design: an educational and methodological guide / E. Yu. Zaikova. Moscow: RUDN, 2015. - 68 p.: ill.

7. Nefedov V. A. Urban landscape design / Nefedov V. A.: Textbook. - St. Petersburg: "Lubavitch", 2012. - 320c: ill.

8. The Contemporary Garden. Phaidon Press Limited. ISBN 978071484958 4- 2009. $111 \mathrm{p}$.

9. Kroeger, Susanne Isabel. Park at the former Northern Station, Berlin. Topos 67, 2009. The International Review of Landscape Architecture and Urban Design, p.15

10. www.archdaily.com

11. Zaykova Elena. 2019, Healing landscapes in the multyfunctional hybrid objects 2019 Proceedings of the Annual International Conference on Architecture and Civil Engineering, Singapore, Scopus. https://www2.scopus.com/authid/detail.uri?authorId=57203435530

12. Zaykova Elena. 2019, Formation methods of hybrid urban spaces in the historic city center. FORM 2019 E3S Web of Conferences, Uzbekistan, Scopus. https://www2.scopus.com/authid/detail.uri?authorId=57203435530 
13. Resourse is: https://www.world-architects.com/en/projects/view/suzhou-zhenshan-park (13.07.2020)

14. William S. Saunders (Ed.). Designed Ecologies The Landscape Architecture of Kongjian Yu. ISBN 978-0346-0738-4. www.birkhouse.com , pp.255

15. www.asla.org (27.02.2021) 